\title{
O afeto como um processo de desenvolvimento ecológico
}

\section{Affection as an ecologic development process}

\author{
Eva Diniz ${ }^{1}$ \\ Silvia Helena Koller ${ }^{2}$
}

\begin{abstract}
RESUMO
O presente artigo descreve a importância do afeto como um dos elementos essenciais para o desenvolvimento humano e, por isso, considerado como intrínseco à Abordagem Bioecológica do Desenvolvimento Humano, formulada por Bronfenbrenner. $\mathrm{O}$ afeto traduz-se pela capacidade do ser humano estabelecer relações, nas quais se criam vínculos e, por esse motivo, poderá ser descrito como um processo do desenvolvimento ecológico. Assim, neste artigo, a presença do afeto nas relações foi proposta como um elemento imprescindível na efetividade dos processos proximais. Além disso, o afeto foi descrito como um dos fatores que asseguram a continuidade do processo desenvolvimental ao longo das várias fases que compõem o ciclo de vida e poderá ser considerado como o principal componente de superação da mudança, ao longo do desenvolvimento. $\mathrm{O}$ afeto, como elemento de desenvolvimento, resulta da interação do indivíduo com o meio em que está inserido. Nessa perspectiva, foi um elemento considerado transversal aos vários sistemas da Abordagem Bioecológica: microssistema, mesossistema, exossistema e macrossistema, nos quais se discutiu a importância do afeto em cada um desses níveis. Por fim, destacou-se a necessidade de estabelecerem-se relações afetivas ao longo do tempo, para que possam ser fortalecidas as capacidades de adaptação às diversas exigências, dificuldades do desenvolvimento humano e, assim, o afeto constitui-se como um elemento que assegura estabilidade e segurança no decorrer desse processo.

Palavras-chave: Afeto; Teoria Bioecológica do Desenvolvimento Humano;
\end{abstract}

1 Mestranda, CEP-RUA, Instituto de Psicologia/UFRGS, evadiniz@gmail.com.

2 Doutora, CEP-RUA, Instituto de Psicologia/UFRGS, silvia.koller@gmail.com. 
Processos Proximais; Mudança; Estabilidade.

\begin{abstract}
The present paper describes emotional development as one of the most important aspect that increases and guides human development. It could be considered as an important "layer" of the development, as it is referred by the bioecological systems theory, proposed by Bronfenbrenner. The abilities to establish relationships depend on emotional aspects, and might be seen as an ecological developmental process. The presence of emotional aspects in relationships was seemed as an essential element that effectively ensures proximal process, in which attachments arises. Besides, emotions were described as important resources employed to lead changes that happens during one's life. As a constituent of human development, emotional development derives from individual interactions with immediate environment by which one is surrounded. In this perspective, it was regarded as an element to the various contexts or systems stressed by Ecological Theory, including the microsystem, mesosystem, exosystem, and macrosystem. Finally, it was emphasised the need to establish emotional relationships over time to strengthen one's abilities to adapt through the life circle. Thus, emotional development constitutes as an element to ensure the stability and safety in this process.
\end{abstract}

Keywords: Affection; Bioecological Systems Theory; Proximal Process; Change; Stability.

\title{
Introdução
}

O presente trabalho pretende discutir o afeto como um elemento imprescindível e inerente a um desenvolvimento humano saudável e harmonioso. $\mathrm{O}$ afeto traduz-se pela capacidade de o ser humano estabelecer relações e criar vínculos. Característica que está presente ao longo de toda a obra de Bronfenbrenner, expressa por aquilo a que o autor chamou de processos proximais. Além disso, é através dos afetos que o ser humano se relaciona e vai além da sua individualidade e finitude. Já que, apesar de o desenvolvimento humano ser um processo individual e único, ele necessita do outro para que ocorra, perante a estimulação mútua, de sentimentos, afetos e experiências (STERN, 1985; 1992).

O desenvolvimento humano caracteriza-se pela interatividade entre os processos de mudança e de continuidade ao longo das várias fases do ciclo vital. 
Essa perspectiva é aprofundada por Bronfenbrenner (2001; 2005) que apresenta a continuidade e a mudança, como ocorrendo não só no próprio indivíduo, mas também no grupo social e na cultura de onde provém. Além disso, a própria passagem do tempo é um elemento de mudança. Contudo, é pela presença de certas características se manterem estáveis, que é possível ultrapassar a mutabilidade das fases desenvolvimentais. O estabelecimento do vínculo, de uma relação de afeto estável e contínua, pode ser considerado o principal elemento de superação da mudança.

Na Abordagem Bioecológica do Desenvolvimento Humano proposta por Bronfenbrenner (1977; 1988; 2001; 2005) há um posicionamento relativamente às restantes teorias da Psicologia do Desenvolvimento, as quais tendem a encarar a pessoa ou o ambiente como os únicos produtos do desenvolvimento. Pelo contrário, Bronfenbrenner considera o desenvolvimento como um processo recíproco, resultante da interação dos vários sistemas que o compõem. Assim, a transição entre cada um desses ambientes e a qualidade relacional nele estabelecidas influenciarão o trajeto desenvolvimental (BRONFENBRENNER, 1977).

Essas transições incluem as principais mudanças por que passa o ser humano, como a passagem de bebê a criança, criança a adolescente e depois adulto. Cada uma dessas "passagens" inclui o cumprimento de tarefas específicas, as quais estão dependentes das "ajudas" exteriores; em particular, a capacidade dos outros se articularem e responderem de acordo com as necessidades sentidas. Ao fazê-lo estarão a proporcionar um desenvolvimento saudável, promovendo a capacidade de autonomização do indivíduo (BRONFENBRENNER, 1977). O autor enfatiza, ainda, que as mudanças não ocorrem apenas na infância, mas ao longo de todo o ciclo de vida, já que cada uma das etapas vitais tem especificidades e tarefas próprias, nas quais é fundamental a interligação dos múltiplos sistemas em que o ser humano transita. No caso de isso não acontecer, esse desenvolvimento poderá sofrer constrangimentos, uma vez que o indivíduo se poderá sentir sem recursos externos aos quais possa recorrer, de forma a superar a mudança e a adversidade.

A Abordagem Bioecológica do Desenvolvimento Humano, desde sua primeira proposição em 1977, postula o desenvolvimento como um processo interativo, entre o indivíduo e o meio (contexto) no qual está inserido. Esse meio foi conceitualizado, por Bronfenbrenner (1977), em quatro níveis distintos: micro, meso, exo e macrossistema, que se influenciam mutuamente, assim como ao indivíduo que nele está inserido.

O microssistema é o ambiente em que se estabelecem relações diretas face a face. Assim existem tantos microssistemas como os ambientes frequentados, como por exemplo, família, escola, emprego, grupo de amigos etc. A agregação 
desses vários microssistemas origina o mesossistema. Embora haja ambientes que não são diretamente frequentados pelo indivíduo, eles existem e influenciam também o seu desenvolvimento: exossistema. Ele pode ser exemplificado pelo ambiente de trabalho dos pais, ao qual a criança não acede diretamente, mas é influenciada por ele, já que a qualidade desse ambiente influenciará a disposição dos pais e, consequentemente, a tonalidade afetiva que constituirão na relação com os seus filhos. Por fim, vem o macrossistema composto pelas leis, regras e normas de uma determinada sociedade. Por exemplo, as sociedades contemporâneas têm preocupação pelo desenvolvimento infantil, considerando-se que um bom desenvolvimento não envolve, somente, cuidados físicos e funcionais, mas também afetivos e relacionais.

Com essa proposta, Bronfenbrenner e seus seguidores (1977; 1995; BRONFENBRENNER; EVANS, 2000; BRONFENBRENNER; MORRIS, 1998) contextualizaram o desenvolvimento como um processo interativo, no qual o ser humano não é encarado como um receptor das características ambientais, mas antes um elemento ativo, com capacidade de intervir no seu meio e alterar as suas circunstâncias. Essa perspectiva foi fortalecida em 1995, quando o autor introduziu o conceito de processos proximais. Os processos proximais caracterizam-se pelo estabelecimento de uma interação recíproca, progressivamente mais complexa, entre um organismo humano e as pessoas/ objetos do seu ambiente imediato, em que ambas as partes se mantém ativas e se estimulam mutuamente.

Para que o processo proximal seja considerado efetivo terá que ocorrer numa base regular e em vários períodos de tempo (BRONFENBRENNER, $1988 ; 1995 ; 2001 ; 2005)$ e ter sentido e significado para a pessoa em desenvolvimento. Com esse conceito foi reforçada a importância da presença de uma figura estável, que estimule a relação ao longo do tempo. É com essa relação que o verdadeiro desenvolvimento ocorre. Apesar disso, a compreensão desse desenvolvimento vai além da sua observação direta, assim como da observação do comportamento interativo de duas ou mais pessoas num mesmo ambiente. Pelo contrário, é necessário considerar os múltiplos sistemas interativos aos quais o indivíduo tem acesso, assim como, as diferentes relações que estabelece em cada um deles (BRONFENBRENNER, 1977).

As relações interpessoais necessitam de reciprocidade para que haja efetividade nos processos proximais e promoção do desenvolvimento. Além disso, é necessária a estimulação da atenção, exploração, manipulação e imaginação dos indivíduos, de forma que a atividade se mantenha "ligada" ao longo do tempo e se constitua como uma interação recíproca. O desenvolvimento, tanto emocional como intelectual, físico e afetivo necessita de relações que se tornem mais complexas e nas quais se possa intervir diretamente (BRONFENBRENNER, 
2001; 2005). De acordo com o autor (2001; 2005), é por haver este envolvimento recíproco entre o indivíduo e o seu meio que ocorrem transformações e, assim, o indivíduo sofre influência do ambiente, mas é também influenciado por este.

O estabelecimento do processo proximal mobiliza as características individuais da pessoa em desenvolvimento, do ambiente na qual a pessoa está inserida e do tempo em que os processos proximais ocorrem. As características da pessoa influenciam o curso dos processos proximais e, consequentemente, a capacidade interacional do indivíduo com o meio. Existem três tipos de características individuais: as disposicionais; os recursos bioecológicos; e as características de demanda. O primeiro aspecto refere-se às disposições individuais mobilizadas nos processos proximais que asseguram a sua continuidade. Os recursos bioecológicos associam-se à habilidade, experiência e conhecimento para conduzir o processo proximal a um novo nível de conhecimento. Finalmente, a demanda associa-se aos aspectos que encorajam ou desencorajem reações do ambiente, com o objetivo de promover ou impedir o desenvolvimento daquele processo proximal. Nesse sentido, entende-se que as características da pessoa estão presentes nos vários microssistemas em que circula (BRONFENBRENNER; MORRIS, 1998).

As múltiplas pesquisas analisadas por Bronfenbrenner e Morris (1998) sobre desenvolvimento humano e as características que o influenciam revelaram que há uma continuidade na reciprocidade entre o indivíduo e o seu meio, em que se recorre aos elementos que o constituem como "espelhos", a partir dos quais o indivíduo se avalia. Essa avaliação toma especial importância na infância, período em que a criança se vê a partir dos “olhos dos outros”, nomeadamente nos padrões interativos estabelecidos. Nessa perspectiva, os autores (1998) defendem que a qualidade do desenvolvimento será fortemente influenciada pela capacidade relacional e os afetos que nela predominam.

A relação que a criança estabelece com o meio exterior, em particular com as suas figuras cuidadoras, irão permitir-lhe definir um modelo relacional interno. Esse modelo será de confiança e segurança, no caso dessa figura ter uma ação contingente e constante às necessidades da criança, ou insegura, se essas ações forem desadequadas ou se tornarem imprevisíveis (AINSWORTH; BELL; STAYTON, 1974; 1983; BOWLBY, 1969; 1984). As relações construídas no futuro recorrerão ao modelo internalizado pela criança, a partir das suas primeiras relações. Nessa relação inicial, a criança aprenderá que expectativas poderá ter dos outros e, consequentemente, de si mesma (BOWLBY, 1969; 1984; BRONFENBRENNER; MORRIS, 1998; STERN, 1985; 1992).

A capacidade do bebê para intervir no seu ambiente foi explorada por Brazelton e Nugent (1995). Nesse estudo, os pesquisadores confirmaram as inúmeras capacidades do bebê, nomeadamente a preferência pelo rosto humano, 
em detrimento de outras formas, mas também do reconhecimento da própria mãe. Com essas pesquisas, os investigadores verificaram, também, conforme pressuposto por Bronfenbrenner, a capacidade do bebê para desencadear a relação. Esses resultados traduzem as competências do bebê, revelando que ele não é um receptor, mas também um estimulador relacional, comprovando a sua capacidade de interagir com o meio.

Não obstante, o meio terá que oferecer condições propícias a esse desenvolvimento, pela disponibilidade para a relação, acompanhada de uma sintonização afetiva adequada (STERN, 1985; 1992). Ao nível do microssistema é esperado que as figuras com quem o ser humano se relaciona face a face se revelem disponíveis, com a capacidade de mobilizar afetos positivos na interação. Esse aspecto é importante, na medida em que a qualidade relacional será um importante contributo para o desenvolvimento futuro (BRONFENBRENNER; EVANS, 2000). Apesar disso, os autores salientam que, dada a interatividade do sistema de desenvolvimento e dos vários elementos que o compõem, no caso desta qualidade relacional ser desadequada num dos microssistemas, poderá ser minimizada pela boa qualidade relacional nos outros em que se insere.

A influência do ambiente sobre o desenvolvimento foi explorada num estudo realizado por Elder $(1974 ;$ 1997) com crianças que nasceram e cresceram durante a Grande Depressão. Nessa pesquisa, observou que os participantes que tinham entre oito e doze anos, na sua maioria, revelaram capacidade para ultrapassar a adversidade, pela capacidade criativa e inovadora para criarem novas soluções. Contudo, os participantes que nasceram durante a Grande Depressão, ao longo do seu desenvolvimento, revelaram maiores dificuldades interacionais, menores níveis de autoestima e maiores indicadores de depressão. Esses resultados traduzem como a fragilidade do macrossistema se reflete em todos os outros níveis, inclusive no microssistema, no qual, devido à escassez de recursos exteriores, se estabelecem relações mais pobres e menos contingentes. Com esses resultados é fácil entender a influência do ambiente nas relações estabelecidas e no desenvolvimento do afeto das pessoas.

Diretamente associado ao ambiente e ao tipo de desenvolvimento nele "produzido" estão o tipo de emoções produzidas. Indivíduos que se desenvolveram num ambiente considerado favorável tendem a expressar emoções consideradas positivas, como gratidão, amor e interesse pelos outros (PALUDO; KOLLER, 2006). A análise dos resultados sugere mesmo que as emoções positivas tendem a ser favoráveis ao aparecimento de outras, também positivas e a gerá-las naqueles com quem a pessoa convive.

Considerando que o afeto positivo pode ser entendido como a capacidade de a pessoa "sintonizar no outro" e, assim, responder de forma adequada (STERN, 2005), ela estará intimamente relacionada com o ambiente de desen- 
volvimento, em particular com as relações que nele se estabelecem. Ou seja, a capacidade de gerar processos proximais em nível de microssistema.

\section{O afeto como elemento do desenvolvimento}

O ser humano caracteriza-se pela capacidade de constantemente se adaptar a um ambiente e suas mudanças ao longo do tempo (BRONFENBRENNER, 2005). Essa capacidade de adaptação é justificada pelo estabelecimento dos processos proximais, que se traduzem pelo estabelecimento de uma relação recíproca considerada, pelo autor, a propulsora do desenvolvimento. Além disso, o ser humano pode, também, ser descrito pela sua complexidade, as suas inúmeras possibilidades desenvolvimentais, a sua capacidade de criar, sentir, pensar, mas também, de atuar (BRONFENBRENNER, 1988; 2001; 2005).

Essas múltiplas oportunidades de desenvolvimento ainda permanecem longe de uma total compreensão dos pesquisadores, nomeadamente na área da psicologia. Inúmeras teorias surgiram para tentar explicá-las e justificá-las. Apesar de este ainda não ser um campo de conhecimento comprovado e estar longe da unanimidade, é pressuposto que a complexidade humana está intrinsecamente associada ao meio no qual o ser humano se desenvolve, desde os seus primeiros momentos de vida até a sua morte. Ou seja, o desenvolvimento humano é algo que nunca termina, é um processo em constante evolução e influenciado pelo meio em que ocorre. Nesse processo, os afetos são algo que se constituem como determinantes para o sucesso desenvolvimental. É através dos afetos que o ser humano se reconhece e, assim, pode se relacionar e ligar-se ao outros e são, também, esses afetos que influenciam o curso vital (STERN, 1985; 1992).

A experiência é, também, um elemento fundamental na definição do modelo bioecológico (BRONFENBRENNER, 2001; 2005). Através da experiência, a pessoa tem capacidade para apreender as propriedades do contexto, não só de uma forma objetiva, mas em particular de forma subjetiva. Assim, um mesmo acontecimento pode ser interpretado de forma diversificada, pelas várias pessoas que o experenciam. São essas diferentes formas de apreensão que direcionarão e conduzirão ao desenvolvimento individual. É nessa perspectiva que o autor sustenta que as experiências vividas são formadas por duas componentes dinâmicas que se interrelacionam: a fenomenológica e a experencial. Esta refere-se ao acontecimento concreto, por exemplo, o nascimento. A componente fenomenológica traduz a forma como esse acontecimento é vivido e avaliado pela pessoa, a sua subjetividade, nomeadamente, os afetos e sensações a ela associados. Ou seja, é a experiência individual daquilo que acontece. Por esse motivo, entende-se que esses fatores se relacionam entre si e influenciam a forma como o ambiente ecológico é apreendido e as mudanças ocorridas ao longo do 
ciclo de vida. Muitas vezes, esses dois componentes atuam em sentidos contrários, provocando vivências contraditórias na própria pessoa que as experiencia. Dessa forma, é fácil entender que tanto a experiência subjetiva como objetiva exercem uma forte influência no curso desenvolvimental.

Nesse sentido, entende-se que o processo proximal para ser um efetivo motor desenvolvimental terá que ter uma base relacional, de partilha afetiva. Para que a atividade se prolongue ao longo do tempo, com o interesse mútuo dos participantes é necessária a criação de um vínculo que mantenha os elementos ligados entre si, com garantia de estabilidade e reciprocidade entre as partes. Bronfenbrenner (2005) exemplifica alguns dos processos proximais que podem ser estabelecidos desde os primeiros momentos de vida e que se prolongam durante o desenvolvimento. Por exemplo, dar de mamar, confortar, brincar, contar uma história etc., são momentos interativos que constituem um processo proximal, na medida em que duas pessoas se relacionam partilhando uma atividade comum, na qual se estimulam mutuamente. Mas para que seja efetiva é necessário que se estabeleça ao longo do tempo e que se transforme e atualize em função das exigências de desenvolvimento de cada um dos elementos que constituem a relação. Não obstante, essas são situações que vão além da situação experencial em si e mobilizam componentes subjetivas do ser humano, como os seus sentimentos e emoções. Ao alimentar, brincar ou confortar uma criança são ativados sentimentos como cumplicidade, ternura, carinho que irão mobilizar acontecimentos passados e ser transportados para o futuro, constituindo a especificidade daquela relação. Assim, a forma, o poder, o conteúdo e a direção dos processos proximais são variados e produzem desenvolvimentos diversificados, em função das características da pessoa, do contexto e da forma como tudo isto é apreendido pelo ser em desenvolvimento. Por esse motivo, se considera que a ocorrência de acontecimentos passados, quer negativos quer positivos, se tornam como contributos para o delineamento do curso de vida.

O estabelecimento desses laços recíprocos mobiliza a criança para o desenvolvimento de atividades no seu meio físico, social e simbólico, condutores da sua atividade exploratória, manipuladora, criativa e imaginativa. Essa capacidade começa a desenvolver-se desde o nascimento do bebê, mas pelo sétimo mês de vida surge uma perspectiva organizadora, na qual a criança passa a aperceber-se da existência de outros, possuidores de estados mentais subjetivos, com sentimentos, motivos e intenções diferentes dos seus; compreende que os acontecimentos físicos e relacionais são sustentados por estas entidades subjetivas. Ao aperceber-se disso, a criança passa a ver-se como diferente do outro: está aberto à intersubjetividade. Logo o seu relacionamento deixa de ser ao nível do eu nuclear, passando ao domínio de relacionamento intersubjetivo (STERN, 1985; 1992). 
Nessa perspectiva, Bronfenbrenner vai ao encontro de outros autores que referem a importância de um terceiro elemento na relação que se constitui. Esse terceiro elemento terá a função de apoiar socialmente e afetivamente o principal cuidador, mas também de oferecer à criança outro estilo relacional, aumentando e complexificando as suas possibilidades relacionais e vinculativas. Assim, é importante destacar como o próprio desenvolvimento parental é influenciado pelo comportamento e desenvolvimento dos seus próprios filhos, o que mais uma vez reforça a ideia do desenvolvimento como um processo dinâmico, influenciado pelos vários sistemas e elementos que o constituem. Nessa perspectiva, percebe-se que, ao longo do ciclo de vida, os afetos constituídos possam sofrer inúmeras flutuações ao longo do tempo, influenciado pelas pessoas e o contexto no qual se desenvolve. Por exemplo, se, no seu processo desenvolvimental, a criança se sentir como um objeto de cuidado, ao qual são dirigidos momentos de atenção plena e se constituírem efetivos processos proximais, será uma criança que se tornará num adolescente e adulto com capacidade de retribuir esses sentimentos, de permanecer ligado às suas figuras de referência e criar novos elos relacionais.

Numa pesquisa na qual se investigaram as características familiares que promovem um desenvolvimento saudável encontrou-se: apoio emocional, presença de práticas disciplinares coerentes e a existência de uma rede de apoio (DE ANTONI; KOLLER, 2001). Ou seja, elementos que propiciem o estabelecimento de relações em que estejam presentes aspectos como a compreensão, tolerância. Por outro lado, o mesmo estudo identificou que descontrole nas relações familiares, falta de acolhimento e de responsabilização são elementos que poderão ser perturbadores ao desenvolvimento.

Os contextos relacionais exercem uma interferência no desenvolvimento dos afetos, já que são resultado de um estado emocional, fortemente influenciados pela interação com o contexto social. A concepção atual de infância (macrossistema) descreve a necessidade de relações estáveis e amorosas, em partícular com as crianças, à qual se dirige muita atenção e proteção. Não obstante, nem sempre é fácil proporcionar este espaço de desenvolvimento harmonioso, de continuidade, atenção e reciprocidade emocional pelas próprias condições de vida. A licença maternidade é reduzida e apenas para um dos elementos e, após esse período, há a necessidade de se retomar a intensa jornada de trabalho que, nem sempre, permite a disponibilidade para o estabelecimento desse tipo de relação. Nesses casos, observa-se como o exossistema é perturbador das relações ao nível do microssistema que vão de encontro ao postulado pelo macrossistema.

A importância de redes de apoio, em que o indivíduo se sinta acolhido, respeitado e valorizado, foi encontrada em múltiplas pesquisas (MORAIS, 2009; DE ANTONI, 2001; PALUDO; KOLLER, 2006; YUNES, 2006) e é um 
dos principais elementos que conduz à superação da adversidade, ao longo do desenvolvimento. Uma pesquisa com crianças e adolescentes que moravam com a sua família ou em situação de rua revelou que ambos os ambientes podem proporcionar bons índices de ajustamento desenvolvimentais. Esse ajustamento depende, precisamente, das relações estabelecidas em cada um desses ambientes (MORAIS, 2009). Dessa forma, entende-se que os múltiplos contextos de desenvolvimento se influenciam mutuamente, em que as ações de um sistema afetam o outro, confirmando a influência das qualidades relacionais estabelecidas entre as pessoas no seu contexto. Essa foi também uma característica encontrada num estudo com idosos (PAULA COUTO, 2007), em que se observou que aqueles elementos que contavam com uma rede de apoio, em que poderiam desenvolver a sua individualidade e eram vistos como pessoas com sentimentos, capacidades e não como "velhinhos", eram aqueles que apresentavam maiores níveis de satisfação de vida. Nesse sentido, é fácil entender como a presença de afetos positivos são imprescindíveis para o desenvolvimento saudável e harmonioso e como a sua importância é transversal a todo o ciclo de vida.

Nessa perspectiva, considera-se que o desenvolvimento afetivo necessita ser estabelecido ao longo do tempo e é através da sua presença que o ser humano terá capacidade para se adaptar às exigências, dificuldades e transformações do seu meio (BRONFENBRENNER, 2001; 2005). É pela capacidade do ser humano interiorizar uma relação, ela própria como elemento de mudança, já que a relação terá que se transformar ao longo do desenvolvimento, em função das características e exigências individuais, que é possível combater os sentimentos de medo, insegurança e depressão que a separação poderia provocar (SOARES, 1996).

O estabelecimento de processos proximais foi definido na abordagem bioecológica como os motores do desenvolvimento (BRONFENBRENNER, 1988). Contudo, para que se estabeleçam como efetivos motores, esses processos proximais terão que se iniciar desde os primeiros momentos de vida do ser humano e isso é possível pela capacidade inata de o bebê se apegar e criar relação. Perspectiva postulada por Bowlby $(1969 ; 1984)$ na qual considera que a necessidade de afeto e proteção, por parte do bebê, se sobrepõe à necessidade do alimento. Contudo, para que essa relação se estabeleça e se desenvolva é necessário uma reciprocidade relacional dos pais (BOWLBY, 1969/1984). Ou seja, estabelecerem-se os processos proximais, através dos quais é possível criar uma base de contato relacional e de estimulação mútua que se vai transformando ao longo do tempo (BRONFENBRENNER, 1988). Nessa perspectiva, os pais ou figuras cuidadoras terão que ser os primeiros a funcionar como base segura pela existência de uma compreensão empática, já que este sentimento de confiança em si e nos outros é fundamental ao longo da vida. É através dele que a criança começa por explorar o desconhecido e só o fará se souber que possui uma base, ou seja, alguém disponível a quem se possa recorrer para procurar consolo e 
proteção quando necessário (BOWLBY, 1969; 1980).

Nessa perspectiva, considera-se essencial a necessidade de estabelecer relações de afeto e confiança, como algo que perpasse todo o ciclo vital. E, assim, torna-se possível manter o sentimento de continuidade em face de todas as mudanças e exigências com que o ser humano se depara ao longo do seu desenvolvimento.

\section{REFERÊNCIAS}

AINSWORTH, M. D. S.; BELL, S. M.; STAYTON, D. J. A ligação filho-mãe e o desenvolvimento social: a "socialização" como um produto da resposta recíproca a sinais. In: RICHARDS, M.P.M. (Orgs.). A integração da criança no mundo social. Lisboa: Livros Horizonte, 1974; 1983. p. 129-171.

BOWLBY, J. Loss: sadness and depression. Middlesex: Penguin Books, 1969; 1980. Attachment and loss, v. 3.

. Apego. São Paulo: Martins Fontes, 1969; 1984. Trilogia Apego e Perda, v. 1.

BRAZELTON, T. B.; NUGENT, J. K. The Neonatal Behaviour Assessment Scale. Londres: MacKeith Press, 1995.

BRONFENBRENNER, U. Toward an experimental ecology of human development. American Psychologist, n. 32, p. 513-533, 1977.

. Interacting systems in human development research paradigms. Present and future. In: BOLGER, N. et al. (Orgs.). Persons in context: development process. Human development in cultural and cultural historical contexts. New York: Cambridge Press, 1988. p. 25-49.

. On the natural of biological theory and research. In: BRONFENBRENNER, U. (Org.). Making human beings human. California: SAGE, 2005. p. 3-15.

DE ANTONI, C.; KOLLER, S. A visão sobre famílias entre as adolescentes que sofreram violência intrafamiliar. Estudos de Psicologia, n. 5, p. 347-381, 2000.

ELDER, G. H. Children of the Great Depression. Chicago: University of Chicago Press, 1974.

. Life course and development. In: DAMMON, W. (Editor-in-Chief); LERNER, R. M. (Volume Editor). Handbook of Child Psychology. v. 1. Theoretical models of 
human development. Nova York: Wiley, 1997.

MORAIS, N. A. Um estudo sobre a saúde de adolescentes em situação de rua: o ponto de vista de adolescentes, profissionais de saúde e educadores. Porto Alegre, 2009. Tese (Doutorado em Psicologia) - Programa de Pós-Graduação de Psicologia, Instituto de Psicologia, Universidade Federal do Rio Grande do Sul.

PALUDO, S. S.; KOLLER, S. H. Psicologia Positiva, emoções e resiliência. In: DELL'AGLIO, D. D.; KOLLER, S. H.; YUNES, M. A. M. (Orgs.). Resiliência e Psicologia Positiva: interfaces do risco à proteção. São Paulo: Casa do Psicólogo, 2006. p. 69-86.

PAULA COUTO, M. C. Factores de risco e protecção na promoção de resiliência no envelhecimento. Porto Alegre, 2007. Dissertação (Mestrado em Psicologia) - Programa de Pós-Graduação de Psicologia, Instituto de Psicologia, Universidade Federal do Rio Grande do Sul.

SOARES, I. Representações da vinculação na idade adulta e na adolescência. Braga, 1996. Tese (Doutorado em Psicologia) - Instituto de Educação e Psicologia, Universidade do Minho.

STERN, D. O mundo interpessoal do bebê: uma visão a partir da psicanálise e da psicologia do desenvolvimento. Porto Alegre: Artes Médicas, 1985; 1992.

YUNES, M. A. M. Psicologia positiva e resiliência: foco no indivíduo e na família. In: DELL'AGLIO, D. D.; KOLLER, S. H.; YUNES, M. A. M. (Orgs.). Resiliência e Psicologia Positiva: interfaces do risco à protecção. São Paulo: Casa do Psicólogo, 2006. p. 45-68.

Texto recebido em 19 de novembro de 2009.

Texto aprovado em 12 de janeiro de 2010. 